\title{
Media use, attention, mental health and academic performance among 8 to 12 year old children
}

\author{
Pedro Cardoso-Leite ${ }^{1 \star}$, Albert Buchard ${ }^{2,3}$, Isabel Tissieres ${ }^{3}$, \\ Dominic Mussack ${ }^{1}$ and Daphne Bavelier ${ }^{2,3}$
}

1. University of Luxembourg,

Department of Behavioral and Cognitive Science,

Esch-sur-Alzette, Luxembourg

2. Université de Genève,

Faculté de Psychologie et Sciences de l'Education (FPSE),

Genève, Switzerland

3. Campus Biotech,

Genève, Switzerland

* Corresponding Author:

pedro.cardosoleite@uni.lu

\section{Acknowledgement}

This research was supported by the Luxembourg National Research Fund (ATTRACT/2016/ID/11242114/DIGILEARN) to PCL and the Swiss National Funds 100014140676 and 100014_159506 to DB. We thank the participating school, teachers, parents and students for their invaluable contribution to this research. We also thank Nuhamin Gebrewold Petros and Anna Flavia Di Natale for their help during the data collection process. The authors declare no conflict of interest regarding this publication. Daphne Bavelier declares she is a member of the scientific advisory board of Akili Interactive, Boston.

\section{keywords}

Media multitasking; Video game play; children; psychological network; cognition; wellbeing; academic achievement 


\section{Abstract}

The rise in digital media consumption, especially among children, raises the societal question of its impact on cognition, mental health and academic achievement. Here, we review the impact of three different ways of measuring technology use-total hours of media consumed, hours of video game play and number of media used concurrently -in a study surveying 156 eight-to-twelve year-old children. At stake is the question of whether different technology uses may have different effects, which could explain some of the past mixed findings.

We collected data over three sessions relating to children's media uses as well as (i) attentional and behavioral control abilities, (ii) psychological distress, psychosocial functioning, and sleep, and (iii) academic achievement and motivation. While attentional control abilities were assessed using both cognitive tests (D2, SART, BLAST) and questionnaires (mind-wandering; Connors), mental health and sleep were all questionnaire-based (K6, Strength and Difficulties Questionnaire-SDQ, Sleep Quality/Quantity). Finally, academic performance was based on self-reported grades, with motivational variables being measured through the grit and the growth-mindset questionnaires. We present partial correlation analyses and construct a psychological network to assess the structural associations between different forms of media consumption and the three categories of measures.

Our results are in line with those observed with adults: children consume large amounts of media and media multitask substantially. Partial correlation analyses show that media multitasking specifically was mostly correlated with negative mental health, while playing video games was associated with faster responding and better mental health. No significant partial correlations were observed for total hours on media. Psychological network analysis complement these first results by indicating that all three ways of consuming technology are only indirectly related to self-reported grades. Thus, technology uses appear to only indirectly relate to academic performance, while more directly affecting mental health.

This work emphasizes the need to differentiate among technology uses when considering their impact on human behavior, It also highlights the importance of characterizing the variety of technology uses that need to be considered, if one is to understand how every day digital consumption impacts human behavior. 


\section{Introduction}

Digital media consumption has increased drastically over the past decades. In the US, 8-12 year old children spend an average of almost 6 hours on digital media every single day (Rideout, 2015) with a substantial fraction of that time spent on multiple media at the same time (29\% for 7 th to 12 th graders; Rideout, Foehr, \& Roberts, 2010). In the European Union, 10-14 year olds spend an average of 2.8 hours a day on digital screens; for 15-19 year olds that number increases to about 3 hours per day (Bodson, 2017). These numbers reflect the ubiquitous role that digital media has come to play in our lives, a role that is very likely to keep growing both in terms of the magnitude and the diversity of digital media consumption. This state of affairs raises increasing concerns about the impact of digital media consumption on cognition and mental health, in particular among children.

Children's media consumption is frequently assessed through total time on media as if all forms of media represented a unitary experience. However, research increasingly suggests that the impact of digital media use on people is complex as it depends on the type of media (e.g., video games, social networks), its content (e.g., fantasy, documentary), the context (e.g., alone, in groups) and the traits of the person consuming media (e.g., age, gender; Orben \& Przybylski, 2019; Bavelier, 2018; Bediou, Rich, \& Bavelier, 2020; Parong \& Mayer, 2018). To understand how digital media impacts children's attentional and behavioral control, mental health and academics requires a finer grained approach.

The present work offers two main contributions. First it presents new experimental data which takes a more granular approach to media consumption by investigating three media consumption indices - total time on media, media multitasking and video game play - and their relationships to children's cognition, health, and academic achievement. Because we collected measures of attentional and behavioral control, mental health, and school related variables on the same children, we can directly evaluate the relative association strength of different media consumption types on different aspects of children's behavior and mental health.

The second contribution of this work is methodological. The literature on the impact of media on behavior faces a number of challenges due to the fact that a) many of the variables considered in this research field correlate with each other (e.g., total hours on media correlates with the amount of media multitasking) and b) there are yet no clear, established causal models in this emerging field (e.g., does multitasking increase impulsivity or do impulsive people multitask more?). We apply psychological 
networks - a relatively new modeling technique - and discuss how it provides a valuable complement to pairwise correlations, linear regressions or mediation analyses.

\section{Previous studies}

The current literature suggests that different forms of media consumption have different relationships and possibly casual effects on human cognition, mental health and various school related variables, among which academic performance. Below we review the literature on these relationships for three main forms or measures of media usage: total time on media, media multitasking and video gaming.

\section{Total Time on Media}

Many studies report that total time on media (all types of media or all screen based media) is associated with adverse attentional and behavioral outcomes (e.g., Twenge \& Campbell, 2018; Allen \& Vella, 2015; Beyens, Valkenburg, \& Piotrowski, 2018; Zhao et al., 2018) and in particular ADHD symptoms. A two year longitudinal study on more than three thousand 15-16 year olds reported that a higher frequency of media use at baseline was associated with a subsequent increase in ADHD symptoms (Ra et al., 2018). Similarly, a meta-analysis on the relation between total time on media and ADHD-related behaviors reported a small but significant association (Nikkelen, Valkenburg, Huizinga, \& Bushman, 2014), as measured by either cognitive tasks, surveys, or observations.

Total time on media has also been linked to various mental health problems. Limtrakul, Louthrenoo, Narkpongphun, Boonchooduang, \& Chonchaiya (2018), for example, explored the relationships between self-reported media use variables and psychosocial health-as measured by the Strengths and Difficulties Questionnaire (Goodman, 1997) which has been linked to Problematic Media Use (Domoff et al., 2019) among 10-15 year olds. Their results suggest that larger amounts of total time spent on media is associated with lower prosocial behaviour scores (measured with items like: the child is "kind to younger children").

The relationship between total time on media and school related variables is less clear, with large-scale studies reporting somewhat contradictory results (e.g., Aypay, 2010; Bulut \& Cutumisu, 2017). A recent meta-analysis on the relationship between overall "screen" media use (i.e., computer, internet, mobile phone, television, video game) and academic performance among children and adolescents (4-18 year olds) reported no relationship between total time on digital media and academic performance (Adelantado-Renau et al., 2019). This same study however, reported that both larger 
amounts of time spent watching television or playing video games were associated with lower academic performance.

\section{Media-Multitasking}

Media multitasking, the simultaneous use of multiple digital media (e.g., listening to music while surfing the web), is both an expanding, recent societal phenomenon (Rideout, 2015; Rideout, Vandewater, \& Wartella, 2003; Roberts, Foehr, \& Rideout, 2005) and a active research topic since the seminal study by Ophir, Nass, \& Wagner (2009) reported that young adults who media multitask heavily exhibited impairments in suppressing distractions across multiple cognitive tests.

Media multitasking has been associated with a broad range of cognitive impairments (Cheever, Peviani, \& Rosen, 2018; Uncapher et al., 2017; Uncapher \& Wagner, 2018; Wiradhany \& Nieuwenstein, 2017), most notably in the attentional and behavioral control domains. Indeed, media multitasking has been associated with higher scores on ADHD surveys (Baumgartner \& Sumter, 2017; Magen, 2017; Uncapher, K. Thieu, \& Wagner, 2016), and higher levels of impulsivity (Minear, Brasher, McCurdy, Lewis, \& Younggren, 2013; Sanbonmatsu, Strayer, Medeiros-Ward, \& Watson, 2013; Shin, Webb, \& Kemps, 2019; Uncapher et al., 2016) and mind-wandering (Ralph, Thomson, Cheyne, \& Smilek, 2014; but see Wiradhany, van Vugt, \& Nieuwenstein, 2019, 2020)in line with these results, Kobayashi et al. (2020) reported differences in functional connectivity of the dorsal attentional network when comparing heavy and light media multitaskers. Furthermore, Ophir et al. (2009) reported that heavy media multitaskers performed worse than light media multitaskers on a range of cognitive tasks, including working memory, task switching and selective attention tasks. A recent neuroimaging study further points to altered memory retrieval in high media multitaskers, owing to more frequent attentional lapses during the processing of memory retrieval cues (Madore et al., 2020). Other studies did not always replicate these results (Alzahabi \& Becker, 2013; Elbe, Sörman, Mellqvist, Brändström, \& Ljungberg, 2019; Minear et al., 2013; Seddon, Law, Adams, \& Simmons, 2018) or suggested that the relationships between levels of media multitasking and cognitive performance may be non-linear (Cardoso-Leite et al., 2016; Shin, Linke, \& Kemps, 2020). The results seem clearer when using surveys and self-reports rather than computerized tests (Magen, 2017): media multitasking has been associated with deficits in self-reported everyday executive and attentional functions (Baumgartner, Weeda, Heijden, \& Huizinga, 2014; Magen, 2017; Ralph et al., 2014; Rogobete, lonescu, \& Miclea, 2020) and could be particularly detrimental at younger ages where executive functions develop intensely (Baumgartner, van der Schuur, Lemmens, \& te Poel, 2018; see also Srisinghasongkram, Trairatvorakul, Maes, \& Chonchaiya, 2020). 
Media multitasking has also been associated with mental health problems. Becker, Alzahabi, \& Hopwood (2013) for instance, reported that media multitasking was positively correlated with depression and social anxiety scores, even after controlling for total time on media and personality traits. High levels of media multitasking have been linked to less sleep, difficulties to fall asleep at night and to keep awake during the day, at school (Calamaro, Mason, \& Ratcliffe, 2009; Pea et al., 2012). However, a longitudinal study found no temporal association between media multitasking and sleep (van der Schuur, Baumgartner, Sumter, \& Valkenburg, 2018), suggesting that the relationship between media multitasking and sleep might not be a direct causal one.

Finally, media multitasking has been linked to negative academic performance and other school related variables. Some studies for instance report that heavy media multitaskers are less efficient academic learners (Loh, Tan, \& Lim, 2016) and may have less grit (Becker et al., 2013) -the ability to maintain perseverance in otherwise aversive tasks, which seems important for academic success (Duckworth, Peterson, Matthews, \& Kelly, 2007). Cain, Leonard, Gabrieli, \& Finn (2016) studied 12-16 year olds and reported that heavy media multitasking was associated with lower academic performance on standardized tests (Math and English) but also with lower performance on computerized executive functions tests and higher impulsivity, along with lesser growth mindset (but neither grit nor conscientiousness, in contrast to other studies mentioned), suggesting that media multitasking is a critical variable to consider when investigating the effects of media (see also Martín-Perpiñá, Viñas i Poch, \& Malo Cerrato, 2019; Luo, Yeung, \& Li, 2020).

\section{Video Game Play}

Several meta-analyses document a positive impact of specifically action video games (as compared to other types of video games) on cognition and in particular, on attentional control (e.g., Powers \& Brooks, 2014; Powers, Brooks, Aldrich, Palladino, \& Alfieri, 2013; Toril, Reales, \& Ballesteros, 2014; Wang et al., 2016; but see Sala, Tatlidil, \& Gobet, 2018). Action video games (AVG), defined in this literature as those in the first or third-person shooter genres, appear to have a greater positive impact on cognition than other types of video games (Bediou et al., 2018). In cross-sectional studies of attentional control on 7-22 year old participants who were classified as either being AVG players or non-video game players, Dye \& Bavelier (2010) observed systematic attentional advantages in the AVG players group. These results are further supported by a few intervention studies on children. For example, Franceschini et al. (2013) and Franceschini et al. (2017) trained 7-13 years old dyslexic children using various minigames for 12 hours, distributed over multiple days. The experimental group played mini-games that used action video game mechanics while the control group played 
mini-games that did not share those features [for a discussion of action game features, see Cardoso-Leite, Joessel, \& Bavelier (2020); cardoso-leitea]. The results showed an improvement in attention (and in reading) only for the experimental group that trained with action-like mini-games. The positive relationship between action video game and cognition is unlikely to hold for video games at large. Indeed, the bulk of intervention studies using action video games makes it clear that not all video games have the same impact on cognition.

The relationship between video game play and mental health are somewhat mixed. A large-scale study ( $\mathrm{N}=2442)$, on $7-11$ year old children for instance, reported that large amounts of gaming (more than 9 hours per week) - but not smaller amounts - were associated with increased conduct problems and reduced prosocial behavior (Pujol et al., 2016). Similar conclusions seem to hold in older children (10-15 year-olds; Przybylski, 2014): compared to children who do not play video games at all, children who play daily for more than 3 hours presented less prosocial behaviors, more conduct problems and decreased life-satisfaction. Children who played between 1 and 3 hours per day were equivalent in those measures as children who did not play at all. Surprisingly however, playing less than 1 hour per day was linked to the opposite pattern of results, suggesting that small amounts of video gaming might in fact have positive effects (Przybylski, 2014). This hypothesis is corroborated by an European study on more than three thousand 6-11 year-olds (Kovess-Masfety et al., 2016) which reported no sign of increased mental health problems as a function of video game play and instead, suggested that gaming might have a protective effect against difficult social relationships.

Finally, there have also been mixed results on the relationship between playing video games and school related variables. After correcting for multiple demographic and trait-level variables, video gaming was linked in Kovess-Masfety et al. (2016) with greater intellectual functioning and school achievement (as rated by the child's teacher) relative to other children in the class. Similarly, Pujol et al. (2016) found a positive association between game play and the teacher's rating of school achievement, but no trend with the number of hours played (see also Posso, 2016). The relationship between video gaming and academic performance remains, however, unclear (Ferguson, 2015): it can be positive, negative or absent depending on various factors (e.g., playing during weekdays versus weekend days (Hartanto, Toh, \& Yang, 2018); playing before versus after school (Drummond \& Sauer, 2020)). As reported in Ventura, Shute, \& Kim (2012), the relationship between gaming and academic outcomes might be U-shaped rather than monotonic, and might for instance depend on the type of game played. There are some reasons to believe that action video games in particular 
might benefit educational outcomes (e.g., Cardoso-Leite \& Bavelier, 2014; Libertus et al., 2017).

\section{The present study}

The reviewed literature shows that different forms of media consumption may affect attentional/behavioral control, mental health and school related variables in different ways. Given the ubiquity of digital media in our lives and the concern that their potential adverse effects may be amplified in younger children, it is imperative to further our understanding of these effects and how they relate to each other.

The reviewed literature is filled with hypotheses about the potential causal relationships between any two constructs, but oftentimes the data to support specific claims is simply missing (Parry \& le Roux, 2019). It is unclear, for example, why exactly total time and media should correlate with attentional/behavioral control, mental health or school related variables. Total time on media is a rough measure of media consumption and there are potentially many confounding variables (e.g., media multitasking habits) which might be responsible for the observed associations. Furthermore, total time on media might have only an indirect effect. For instance, total time on media may affect attention, mental health and school related variables via its negative effects on sleep (Clifford, Doane, Breitenstein, Grimm, \& Lemery-Chalfant, 2020), which might be the real cause of decreased cognitive functioning, mental health and academic performance (e.g., Lange et al., 2017; Stiglic \& Viner, 2019). It appears then, that in order to gain insights into the underlying causes it is necessary to collect for each participant a larger set of measures covering both different aspects of their media usage habits, but also aspects of their cognitive functioning, their mental health and, in the case of children, school related variables. This insight motivated the design of the present study.

The second important insight is methodological and concerns how to best analyse such multivariate data. Previous research mostly used correlation and linear regression analyses to highlight the presence of a (positive or negative) relationship between some form of media use and a variable of interest. Correlations between pairs of variables may be misleading because that correlation might be explained by other variables. Linear regression on the other hand, implicitly assigns causal roles to the variables. Indeed, regressing, for example, academic performance on total hours of media is different from regressing total hours of media on academic performance and seems to suggest that total hours of media causes changes in academic performance. There are of course more advanced multivariate models which adequately treat measures as measures (rather than measurement-free predictors, as is the case in linear regression) 
and explicitly define the directionality of the influence of the variables (most notably, structural equation models which includes mediation and moderation models). However, there is currently no clear understanding of the relationships that might exist between the various constructs to justify a particular causal structure for such models.

Acknowledging both the paucity of evidence for specific causal relationships and the ubiquity of correlations among variables, we turn to a method known as psychological network analysis (Borsboom \& Cramer, 2013; Epskamp, Borsboom, \& Fried, 2018) is best suited for this context. This method is analogous to partial correlation analyses in that it attempts to evaluate the specific association between pairs of variables, albeit within the context of a network of variables. Using this method one may evaluate, for instance, whether there is a direct link between total media time and self-reported grades or whether total media time has an indirect effect on grades by reducing the amount or quality of sleep. Under certain assumptions, the presence of a direct association between two variables in a psychological network may be indicative of a causal relationship between them; however the directionality of the relationship remains unspecified. When there are many possible variables under investigation and no clear theoretical model, the associations highlighted in psychological networks might provide relevant starting points for future studies to investigate causality experimentally. While at this stage, this type of analysis is mostly exploratory, it offers a new perspective on previously reported effects and may constitute a promising avenue going forward.

In this study we collected data on three different self-reported measures of media use (total time on media time, media multitasking and video game play) as well as a collection of measures that have been highlighted in past research; these measures cover attentional/behavioral control, mental health and school related variables. This dataset is interesting because it includes a large set of variables for the same subjects, that is 156 eight-to-twelve year-old children. Although a larger sample size would always be welcomed, such multivariate dataset to qualify media usage in children remains rare in the literature. We first probe the specificity of previously reported pairwise relationships between variables using rather traditional methods, such as partial correlation analysis, before using psychological network analysis. This two-step approach allows us to relate our results to past research while also providing new insights. 


\section{Methods}

\section{Participants}

This study was conducted in a public primary school in the suburbs of Geneva, Switzerland. From the 226 children in the targeted classrooms, we obtained parental consent for 156 children ( 84 boys and 72 girls).

The participants of the current study were children aged 8-12. They were in grade levels $5 \mathrm{P}$ to $8 \mathrm{P}$ within the same school in Geneva (grades 5P to 8P in Geneva correspond roughly to grades 3 to 6 in the United States ("School grade placement," 2019)).

Table 1: Number of children per grade level

\begin{tabular}{lr} 
grade & number of children \\
\hline $5 P$ & 31 \\
$6 P$ & 29 \\
$7 P$ & 44 \\
$8 P$ & 36
\end{tabular}

\section{Apparatus}

We collected data via paper-and-pencil questionnaires completed by the parents and teachers of the children enrolled in this study as well as via cognitive tasks that were completed by the children in their classroom during school time. Below we list the surveys and cognitive tasks that were used.

We included a large amount of paper-and-pencil surveys to span a wide range of dimensions that might be relevant within the scope of this study. This selection included standard surveys from the literature but also custom-made questions that are more exploratory. The surveys were all administered in French translations of their original versions (our translations are available to readers by request). Children were asked to complete these questionnaires with their parents unless otherwise noted.

\section{Questionnaires}

In addition to a general demographic questionnaire-which asked children about their birthdate, gender, handedness, number of siblings, self-reported health state, the languages spoken at home, as well as yes/no questions about difficulties in vision, audition, learning and verbal comprehension and expression-the questionnaires 
included in this study cover broady speaking four categories: digital technology use; attentional problems; mental health and sleep; grades, motivation and beliefs.

\section{Digital Technology Usage}

The media multitasking inventory is an adapted version of the multi-media questionnaire developed by Ophir et al. (2009). We used three main measures from this questionnaire: the total number of hours of media content consumed per day, the media multitasking index (as defined in our study) and the total number of hours of video gaming per day

The video gameplay questionnaire asks about which video games children play, on what device and how frequently ("often", "sometimes", "rarely"). Combined with the reported number of hours of video gaming from the media questionnaire, this survey provides an estimate of how much time is spent on each game category.

\section{Attentional problems}

The Conners Teacher's Rating Scale (Conners, 1997) requires teachers to evaluate their children's school behavior and leads to a score, where a higher value is interpreted as having overall more ADHD-like behavior (e.g., difficulty paying attention or impulsive behaviors).

The Conners Parent's Rating Scale is similar but is filled out by the child's parents.

We assessed mind wandering or the frequency of task unrelated thoughts using the 4-item short survey of Mrazek, Phillips, Franklin, Broadway, \& Schooler (2013).

\section{Mental Health and Sleep}

The K-6 distress scale (Kessler et al., 2003) evaluates non-specific psychological distress with items relating to anxiety and depression; a higher score reflects higher levels of emotional distress.

This Strength and Difficulties questionnaire (Goodman, 1997) covers 5 dimensions of children's behaviors, emotions, and relationships and provides a total score, with higher values corresponding to having more emotional difficulties.

We also included a custom-made sleep questionnaire from which we compute a score, with higher values indicating better sleep and less fatigue. 


\section{Grades, Grit and Mindset}

The custom-made grades questionnaire asked children to self report their grades (the question translates to "what do you think is your average general grade at school?"), and their grade satisfaction ("I have good grades at school" with response on a fourpoint Likert scale going from yes to no).

The grit questionnaire measures perseverance and passion for long-term goals (Duckworth et al., 2007), with a higher score corresponding to greater perseverance.

Finally, the Theory of Intelligence (or mindset) questionnaire measures childrens' beliefs about the potential of intelligence to improve (Dweck, 2008); a higher score indicates a "growth mindset" or a stronger belief that intelligence can be improved.

\section{Cognitive Tests}

We report here 3 of the 5 cognitive tasks completed by the children in this study (one task was excluded because technical problems compromised the integrity of the data, and the other because it was part of an exploratory study that is unrelated to the present study). Each of these 3 tasks taps mostly attentional processes and gives rise to three main measures (for a total of 9 measures across the three tasks): a response speed index (how fast children perform), an inattention index (how often they fail to respond when they should have) and an impulsivity index (how often they respond when they shouldn't have).These indices were then z-scored within tasks and averaged across tasks to provide an overall score on speed, inattention and impulsivity.

\section{D2 cancellation task}

The D2 task is a paper and pencil task designed to measure selective attention (Brickenkamp \& Zillmer, 1998). Participants were given a sheet of paper filled with symbols composed of the letters "d" or "p" with zero, one or two bars above and/or below the letter. Children were orally instructed to circle every symbol that comprises the letter "d" that is surrounded by exactly two bars (e.g., one above and one below; two above and none below).

\section{Sustained Attention to Response Task (SART)}

In the SART task (Robertson, Manly, Andrade, Baddeley, \& Yiend, 1997) a digit (1-9) appears for $250 \mathrm{~ms}$ on the screen center every $1.150 \mathrm{~ms}$ and children are instructed to tap on the screen in response to any digit except the digit " 3 ". 


\section{Bron Lyon Attention Stability Task (BLAST)}

In the Bron Lyon Attention Stability Task (BLAST) task (Petton et al., 2018), children are first shown a single target letter (e.g., "A") for $250 \mathrm{~ms}$, followed $500 \mathrm{~ms}$ later by a $2 \times 2$ array of letters that did (e.g., "A, K, B, R") or did not (e.g., "X, K, B, R") contain the target letter. They were asked to report on each trial whether or not the target letter was present in the array.

\section{Procedure}

The teachers distributed and collected the consent forms from the parents at the beginning of the school year. Parents could fill out the questionnaires at home with their child and bring them back to the school once they were completed. Teachers also filled out a questionnaire about each of their pupils whose parents consented to the study.

Cognitive tests took place in three sessions (January, March and May; see Supplementary information). Children were tested in their classroom, during school time, in classes including 14 to 16 students at the same time. Each child was seated at a table to complete the pencil and paper tests as well as computerized cognitive tests. Children were allowed to set the screen distance or position as they wished. Each test session lasted about 40 minutes.

\section{Results}

Reliability and descriptive statistics are reported in the Supplementary Materials. Here we first briefly describe some key results about media usage among 8 to 12 year old children before evaluating specific relationships between different forms of media usages, attention, mental health and school related measures.

\section{Media consumption by age and gender}

Total hours of media consumed per day increases with age (Spearman correlation $r=$ $0.35, p=9.7 e-05)$. At age 8 , children consume on average 4 hours and 28 minutes of media per day; at age 12, that number increases to 8 hours and 14 minutes per day. For each additional year of age, total hours of media consumed increases by almost a full hour.

The total amount of media consumed does not differ among boys and girls (Wilcoxon rank sum test with continuity correction, $\mathrm{W}=1808, \mathrm{p}=0.71$ ). This result is confirmed by a linear mixed effects analysis on the hours spent per media by gender $(F(1,116)=$ 
$0.003, p=0.957)$. Yet, this same analysis also shows that some media are consumed more than others $(F(7,812)=16.1, p=6.8 \mathrm{e}-20)$ and differently by boys and girls (interaction effect, $F(7,812)=5.6, p=2.5 e-06)$. More specifically, boys spend more time on video games than girls $(1.1 \pm 0.12 \mathrm{~h}$ /day vs. $0.47 \pm 0.08 \mathrm{~h} /$ day; Wilcoxon rank sum test with continuity correction, $\mathrm{W}=2631, \mathrm{p}=9.4 \mathrm{e}-07$; gender differences for other media are smaller and would not resist multiple comparison correction).

Media multitasking also increases with age (Spearman correlation: $r=0.34, p=0.34$ ). At age 8 , the media multitasking score is 0.66 ; at age 12 , it increases to 1.61 . For each additional year of age, the average number of additional media used simultaneously while using media increases by about 0.24 .

Finally, there is no difference in media multitasking scores between boys and girls (Wilcoxon rank sum test with continuity correction, $W=1427, p=0.613$ ).

Within the age range studied, the number of hours spent on video games each day does not increase with age (Spearman correlation, $r=0.04, p=0.695$ ). Overall, boys spend more time on video games than girls do (mean \pm SEM: $1.1 \pm 0.12$ vs. $0.47 \pm 0.08$ hours per day; Wilcoxon rank sum test with continuity correction, $W=2631, p=9.4 \mathrm{e}-$ 07). A linear mixed effects model on the hours of daily video gaming yields a significant interaction effect between gender and whether the games played were action-like or not $(F(1,186)=12.6, p=4.9 \mathrm{e}-04)$ : boys play more action-like video games than girls ( $W=1837, p=1.0 e-08 ; 0.68 \pm 0.1$ versus $0.13 \pm 0.05$ hours per day) but there is no difference between them when considering time spent on other games $(\mathrm{W}=1010.5, \mathrm{p}$ $=0.535 ; 0.41 \pm 0.08$ vs $0.5 \pm 0.1$ hours per day). 


\section{Attentional Performance by age and gender}

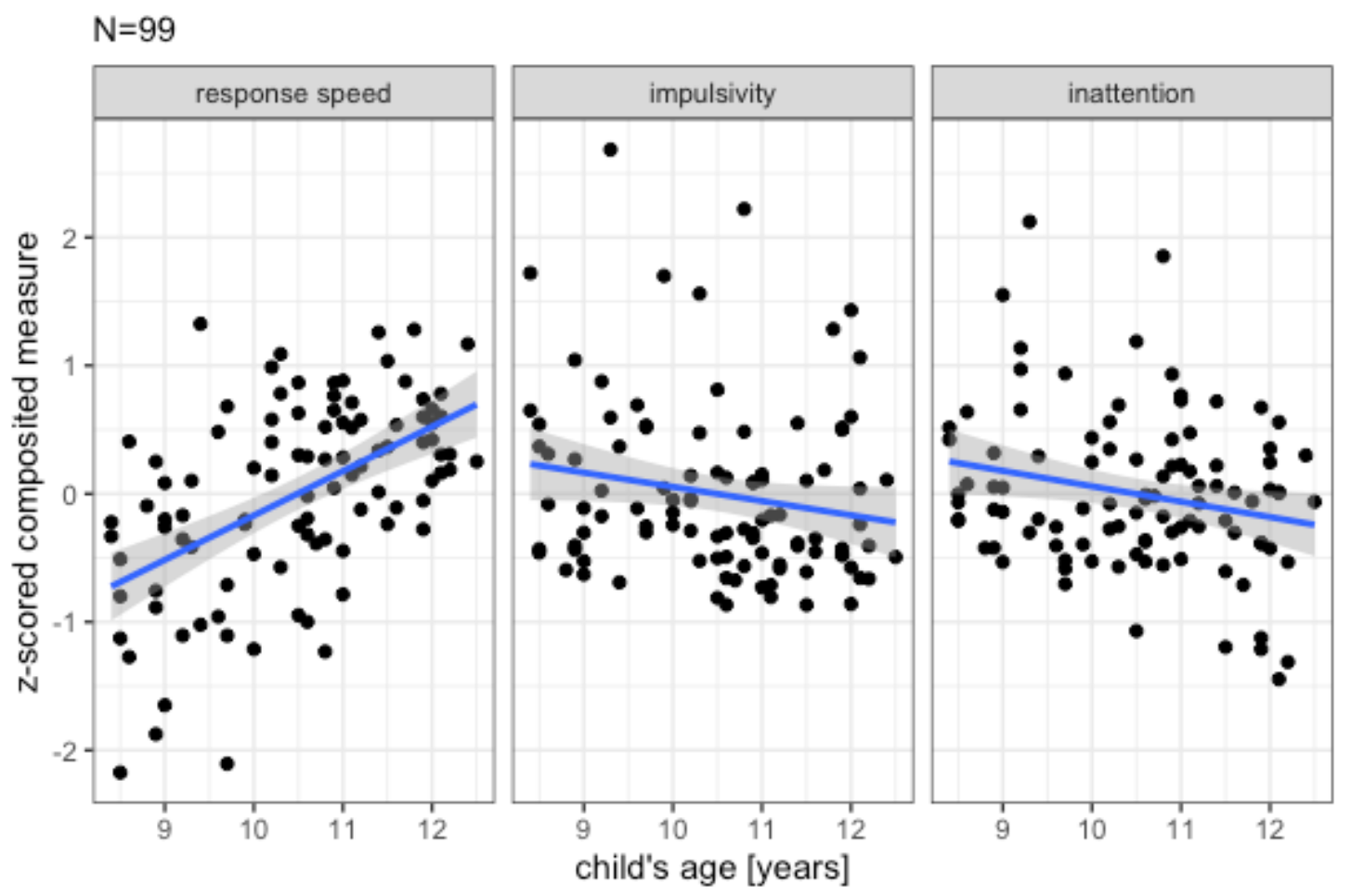

Figure 1: Cognitive performance as a function of children's age.

As children get older, response speed increases (Spearman correlations: $r=0.52 ; p=$ 3.9e-08), impulsivity decreases (i.e., tendency to make false alarms; $r=-0.22 ; p=$ 0.029 ), and inattention decreases numerically although not in a statistically significant way according to the Spearman correlation test (i.e., miss rates; $r=-0.15 ; p=0.133$; see Figure 1). To evaluate the effect of gender, in addition to age, we also ran ANOVAs on the three cognitive indices (regressing separately the three cognitive indices on age, gender and their interaction). These analyses show a significant effect of age on speed $(F(1,95)=38.8, p=1.3 e-08)$, on impulsivity $(F(1,95)=3.65, p=0.059)$ and on inattention $(F(1,95)=5.14, p=0.026)$. The effect of gender was significant on impulsivity $(F(1,95)=6.29, p=0.014$; with boys being more impulsive than girls) and on inattention $(F(1,95)=5.14, p=0.026$; with girls performing better) but not on response speed $(F(1,95)=3.22, p=0.076)$. Finally, in none of the measures did we observe an interaction between age and gender (all $p>=0.208$ ). 


\section{Partial Pairwise Spearman correlations}

\section{Total media time and media multitasking}

As many of the variables are correlated-for example, response speed correlates with total hours of media consumed $(r=0.26 ; p=0.0085)$ but both response speed and total hours of media also correlate with age $(r=0.52 ; p=3.9 e-08$ and $r=0.35 ; p=$ 9.7e-05) - it is not straightforward to interpret correlations between any pair of variables. We thus use partial correlations in an attempt to evaluate the specific relationship between two variables when controlling for age and other types of media use.

We computed the correlation between total hours of consumed media and each of our variables of interest while controlling for media multitasking and age and gender; we also did the reverse, i.e., compute the partial correlation between media multitasking and the variables of interest while controlling for total hours of media, age and gender. This procedure is justified by the fact that media multitasking and total hours of media are strongly correlated $(r=0.48 ; p=8.5 e-08)$.

The partial correlation profiles corresponding to these two cases are shown in Figure 2. Clearly, these results show no correlation between total hours of media and any of the measures of interest when controlling for age, gender and media multitasking. However, when controlling for age, gender and total hours of media, we observe relationships between media multitasking scores and most self-reported measures. High levels of media multitasking are linked to higher levels of distress (K6), lower socio-emotional functioning (SDQ), more behavioral and attentional problems as measured by both Conner's Parents and Conner's Teachers, as well as a reduced quality of sleep and lesser grit. No significant partial correlation is observed between media multitasking and mind wandering, mindset, grades, or any of the cognitive performance measures. 


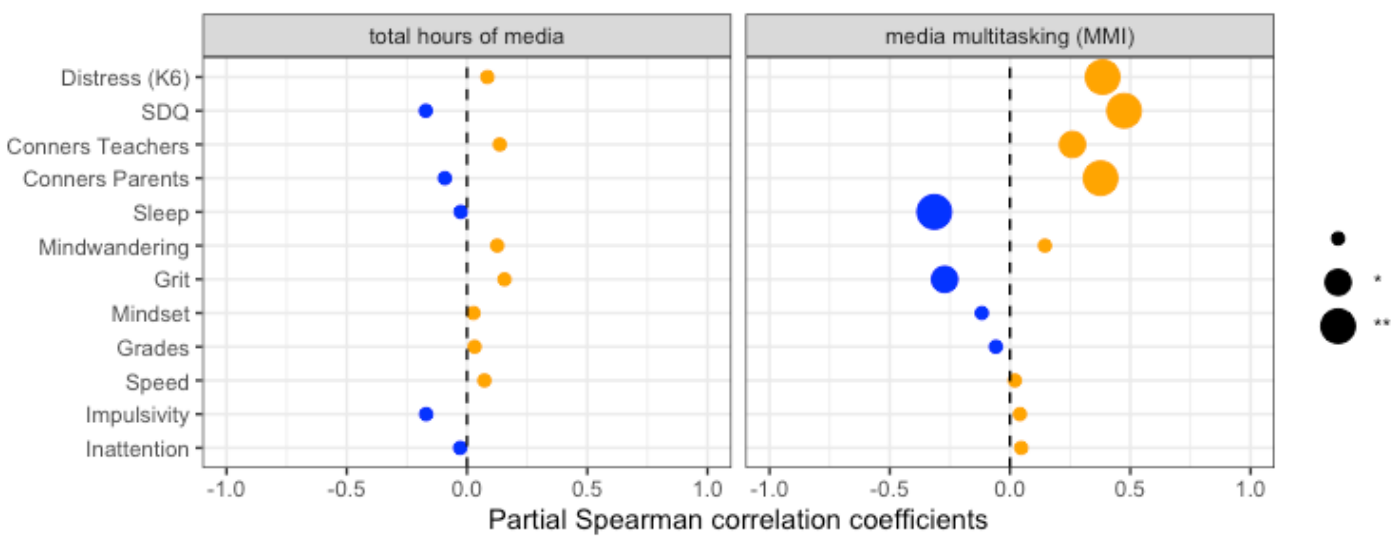

Figure 2: Partial Spearman correlation profiles of total hours of media (controlling for age, gender and MMl; left panel) and media multitasking (MMl; controlling for age, gender and total hours of media; right panel).

\section{Video gaming}

Recall that the reported daily hours of video game play was taken from the media questionnaire and that there was a separate set of questions asking participants to report which games they played and at what frequency. This second questionnaire was used to determine if the games played by the children contained action-like mechanics or not (as well as other video game related data that are not reported here). From our data, we could compute the fraction of time spent on action-like video games versus other games. We then estimated the time spent on those two types of media by multiplying those fractions with the total daily hours of video game play. We excluded from this analysis participants who did not play at all $(n=21)$ or failed to report which specific games they played $(n=10)$.

We evaluated how playing video games relates to cognitive measures and found, in agreement with the literature, that video gaming correlates positively with response speed $(r=0.3 ; p=0.006)$ but neither with impulsivity $(r=-0.04 ; p=0.746)$ nor inattention ( $r=0.03 ; p=0.793)$. The response speed effect appears mostly driven by time on action-like games $(r=0.22 ; p=0.046)$ rather than other types of games $(r=$ $0.13 ; p=0.23$; all other correlations are not statistically significant).

Next, we looked at the relationships between playing video games (overall and separating action and non-action video games) and our variables of interest, while controlling for age, gender, total hours of media and media multitasking score. 


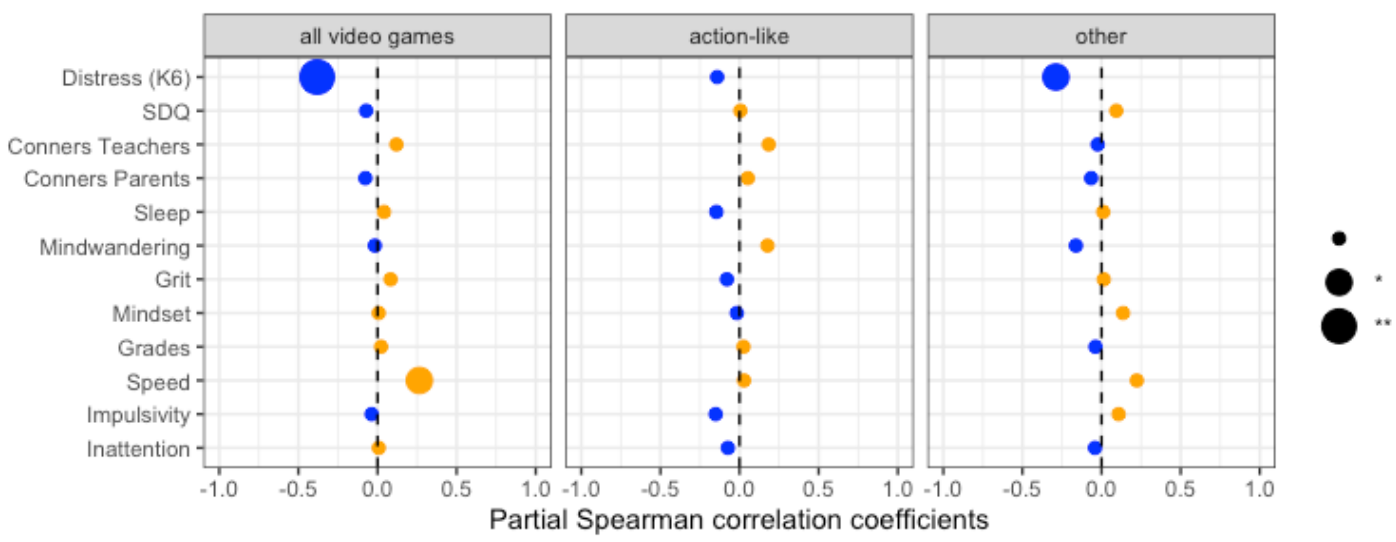

Figure 3: Partial Spearman correlation profiles of time spent on video games (controlling for age, gender and total hours of media and media multitasking). The three panels depict time spent on any kind of video games (left panel) or when considering separately time on action-like (middle panel) and non-action-like video games (right panel).

Overall, more time on video gaming is associated with faster response speed in the attentional control tasks ( $r=0.26, p=0.024, n=77$; see Figure 3 ) without, however, any concomitant increase in error rates that could have been indicative of an increased impulsivity or inattention ( $p$ > 0.756). The largest effect was observed on the K6 distress scale with more time on video game being associated with lower levels of distress $(r=-0.38, p=0.006, n=55)$. These effects were only observed when collapsing all games together; with no clearly dissociable effects between action-like video games and other video games genres. No other reliable effects were observed.

\section{Psychological Network}

A generalization of the data analysis approach presented above consists in evaluating the partial correlations between any pair of variables while controlling for all the remaining variables; such a method is sometimes known as psychological network analysis. The resulting patterns of partial correlations may be represented as a network where nodes represent variables and edges the presence of a partial correlation between them (Epskamp et al., 2018). Nodes connected by an edge therefore indicate a direct relationship between those variables, while indirect relationships are simply any non-direct pathway in the network. The advantage of this approach, compared to Structural Equation Modeling for example, is that it permits to simultaneously take into account a range of variables of interest without having to commit to a particular causal structure, which at this stage of the research remains largely unknown. It provides a picture of the complex relationships between various cognitive, demographic and life- 
style factors that might be a more accurate depiction of reality and less biased by a particular research agenda.

\section{Description of the technique}

Psychological Networks were estimated using the R package bootnet (Epskamp et al., 2018) and $R$ (Team, 2013). The rationale is akin to estimating the partial correlation between each pair of variables while controlling for all remaining ones. However, as the number of possible partial correlations between each pair of variables increases rapidly with the number of variables, there is an increased chance of false positives (when not correcting for multiple testing) or a reduced probability to detect any effect at all (when controlling for multiple testing). An alternative approach, that circumvents these issues, estimates all the partial correlations at once and uses LASSO regularization and the Extended Bayesian Information Criterion to determine which model (with some of the partial correlations set to 0 ) best accounts for the observed data. There are no $p$-values associated with specific edges; rather, the estimated network as a whole, highlights the combination of edges that are reliable.

\section{Variables entered into the analysis.}

Given our limited sample size and in order to limit spurious relationships, we included in this analysis only our primary variables for which we had the largest sample sizes. The eleven variables included in this analysis are the media multitasking score $(\mathrm{N}=$ 110 ), the total number of hours of media consumed each day ("Media Hours", $N=$ 118 ), the number of daily hours of video game play ("Gaming", $N=118$ ), child's age and gender (as "Female", $N=118$ ), self-reported grades ("Grades", $N=117$ ), "Conner's Teachers" $(N=92)$, "Sleep" score $(N=116)$ and the three composite scores from the attentional control task-i.e., "Speed", "Inattention" and "Impulsivity" ( $\mathrm{N}=99)$. 


\section{Network Analysis}

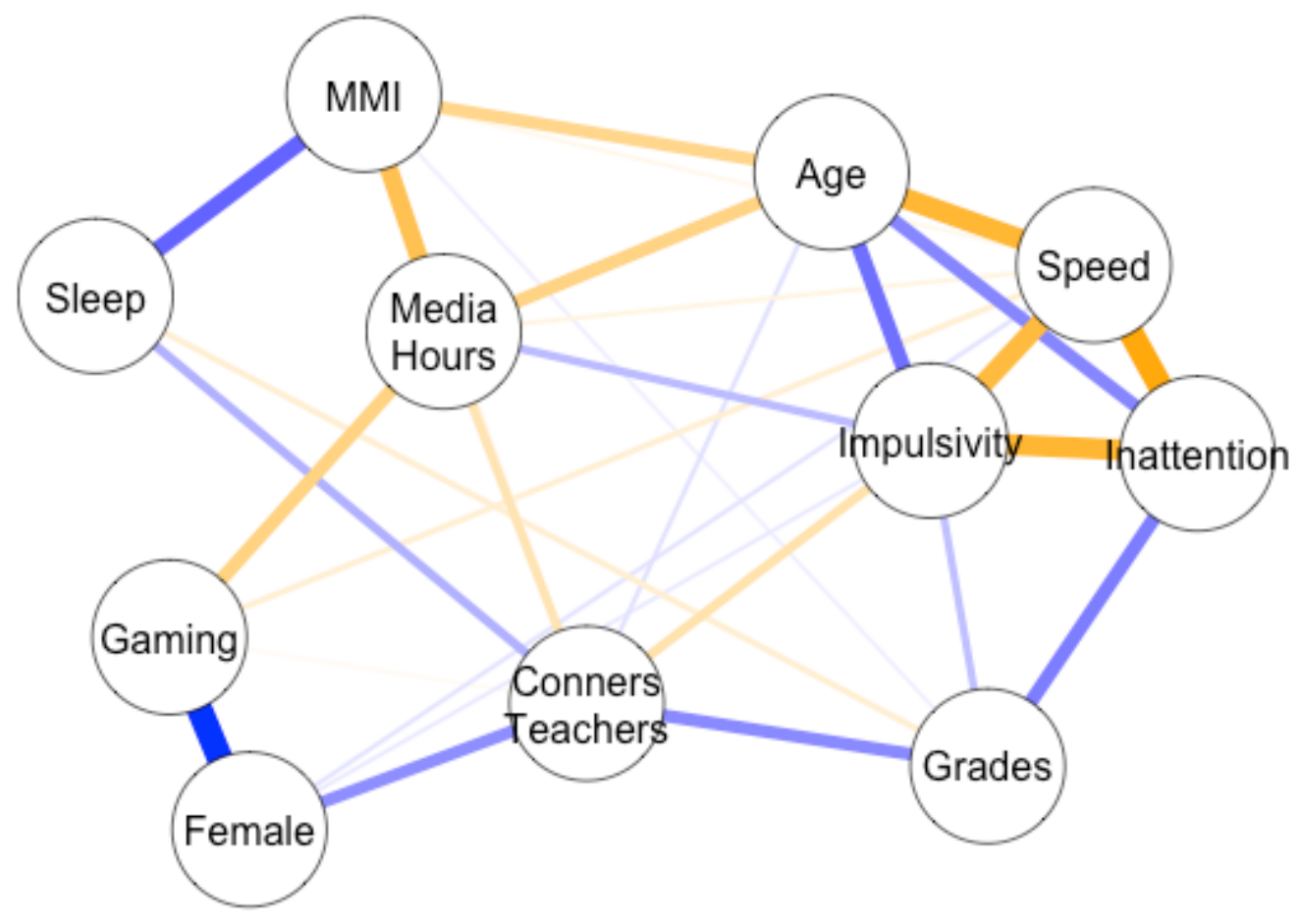

Figure 4: This Concentration Plot represents the network structure estimated on the 11 variables of interest. Nodes represent variables; edges represent the relationship between variables that cannot be explained by the remaining variables. The width and saturation of the edges reflect the strength of the relationship; positive associations are highlighted in orange and negative associations in blue (e.g., higher levels of media multitasking (MMI) are associated with being older, higher number of hours of media and worse sleep quality).

The concentration plot in Figure 4 highlights several noteworthy relationships. First, and as expected, age is strongly associated with the attentional control variables, being linked positively to speed and negatively to false-alarms (i.e., "Impulsivity") and misses (i.e., "Inattention"). Thus, as expected, older children respond faster, and suffer less from impulsivity and inattention. Second, this analysis also confirms the wellknown speed accuracy trade-off. Taking all variables into account, "Speed" is positively associated with "Impulsivity" and "Inattention" as faster participants tend to make more errors. Third, and also as expected, the three measures of technology use are positively related to each other, with time on media (i.e., "Media Hours") being associated with both higher levels of media multitasking ("MMl") and more time spent playing video games ("Gaming"). Interestingly, no direct relationship between "Gaming" and "MMl" is observed. Furthermore, there is a positive association with age 
for both "Media Hours" and "MMI" - indicating greater technology consumption as children get older.

Of greater practical interest are the predictors of "Grades". Both lower "Inattention" and lower "Impulsivity" levels are associated with better grades - "Speed" however is not directly related to grades. Furthermore, grades relate directly to "Conner's Teachers" ratings with, as expected, higher ratings (i.e., higher levels of behavioral issues and attentional deficits) being associated with lower grades. "Conner's Teachers" are associated with "Impulsivity" as measured in the attentional control tasks, which attest to the consistency and validity of these measures. "Conner's Teachers" also relate to the child's gender-with girls receiving better ratings than boys - and to sleep habits - with poor self-reported sleep satisfaction being associated with worse ratings (i.e., higher "Conner's Teachers" scores).

Technology use is found to have little to no direct relationship with grades, except for $\mathrm{MMI}$-higher levels of $\mathrm{MMI}$ are weakly associated with lower grades. Most relationships between media uses and grades appear instead to be indirect: higher levels of $\mathrm{MMI}$ are associated with poor sleep and with more hours of media consumed; worse sleep and more hours of media consumed are associated with worse Teacher ratings, which in turn are associated with worse grades. Total hours of media is only indirectly related to grades via worse teacher ratings. Finally, there are no clear links between gaming and either grades, Conner's Teachers, or sleep. Gaming is only associated with increased response speed, albeit weakly.

\section{Discussion}

There are growing concerns about the potential of digital media to negatively impact everyday life functioning, in particular during childhood. These concerns call for empirical data on media use in children that is both granular (i.e., considering separate forms of media use), comprehensive (i.e., considering simultaneously a wide range of possible outcome variables) and which adequately handles the fact that many of these variables correlate with each other. Here we investigated three main aspects of media consumption behavior - total media hours, media multitasking and video gamingamong a population of 8 to 12-year old children. The present work addresses the relationships between these three distinct forms of media consumption and attentional and behavioral control (measured through both cognitive tests and questionnaires), mental health and sleep, and grades, grit and mindset.

Our results confirm the well-established observation that as children age, they consume more media. In this representative sample of Swiss children, the amount of 
media content consumed each day increased steadily by one additional daily hour per year of age. From ages 8 to 12, the daily hours of media consumed increased from about 5 to 9 hours. This is in line with many reports in the literature (Rideout, 2015), including that of Pea et al. (2012) who used a similar (albeit online) survey on a sample of 3,4618 to 12 year old girls and reported an average of 6.9 hours of daily total media use. This was concomitant with an increase in the number of media used at the same time by 1.4 additional media. In our work, the average number of additional media that children use when using more than one medium at the same time increased from a value of 0.66 at age 8 to a value of 1.61 at age 12 . Notably, girls and boys did not differ in terms of total media time or amount of media multitasking-unlike Baumgartner et al. (2018); Cotten, Shank, \& Anderson (2014)] who reported that girls media multitask more than boys do. Girls and boys did however differ in the types of media consumed, with boys reporting larger amounts of video game play, especially those containing action-like mechanics. The extent to which these differences in media consumption foster gender differences in cognitive skills remains an interesting open question (Bavelier, Green, \& Dye, 2010; Reilly, Neumann, \& Andrews, 2017).

\section{Total media time and its limitations as a metric}

We argue, as have many before us, that total time on media is not a sufficient metric. Total time on media correlates strongly with measures of more specific forms of media use, each of which having their unique, positive or negative impact. This is apparent in the psychological network analysis where total time on media is among the most connected nodes. Yet, this analysis also highlights the distinctness of media multitasking and video gaming, each of them in separate clusters. The shared variance captured by total time on media appears determinant to account of poor attentional behavior. Children who spend more time on media are more frequently reported by their teachers to manifest ADHD-like behavior. Conceptually, this relationship is in line with past research (Nikkelen et al., 2014; Ra et al., 2018; Stiglic \& Viner, 2019). Yet, partial correlation analyses reveal that media multitasking is the likely driver of this effect. We observe no significant relationships between total time on media and any of our outcome variables when controlling for media multitasking, age, and gender. Although these results could appear to contradict those published in the past (Stiglic \& Viner, 2019; Uzun \& Kilis, 2019; Zhao et al., 2018), these past studies used total media time without controlling for other types of media consumption. In contrast to total media time, media multitasking is associated with more frequent ADHD-like behavior as rated by their teachers, when controlling for total media time, gender, and age. 


\section{Media-Multitasking vs. Video Game Play}

Both partial pairwise correlations involving media-multitasking and the psychological network analyses point to an association between media multitasking and poor attentional behavior. The partial pairwise correlations highlight large and significant partial correlations linking media multitasking with numerous adverse, self-reported measures: higher levels of media-multitasking were associated with higher levels of psychological distress (K6), lower levels of socio-emotional functioning (SDQ), worse behavior and attention ratings by both teachers and parents, worse sleep and lower levels of grit. These results are in line with past research reporting an association between media multitasking and increased depression and anxiety among young adults after controlling for total time on media and various personality traits (Becker et al., 2013), or media multitasking and worse socioemotional outcomes and worse sleep among 8- to 12- year old girls (Pea et al., 2012). The psychological network analysis further supports the negative link between media multitasking and worse sleep. Sleep is important because it is known to affect many aspects of our lives, including attentional/behavioral control, mental health and school related variables (for reviews see, Chaput et al., 2016; Owens, ADOLESCENT SLEEP WORKING GROUP, \& COMMITTEE ON ADOLESCENCE, 2014). In agreement with that literature, in our study, children who report worse sleep both have worse grades and receive less favorable attention and behavior ratings from their teachers. A relationship between higher levels of media multitasking and worse sleep has already been reported several times, both in children (Pea et al., 2012) and adolescents (Calamaro et al., 2009; van der Schuur et al., 2018), with some researchers suggesting that sleep is more strongly associated with media multitasking than with total time on media (van der Schuur et al., 2018) - this is also the case here, as we observe no relationship between total time on media and sleep.

Contrary to the analysis on media multitasking, both partial correlation analyses on hours of video gaming (controlling for age, gender, total time of media consumed and media multitasking index) and the psychological network analyses revealed no significant adverse associations. More specifically, we observed no significant partial correlation involving video gaming and socioemotional functioning, attention and behavioral issues as rated by teachers and parents, sleep, mind wandering, grit, growth mindset, grades and either impulsivity and inattention in cognitive tests. Rather, we found positive relationships between time spent playing video games and both faster response speed in our attentional control tests, and reduced levels of psychological distress; indicating that playing video games might have a positive impact on specific measures of cognitive control and mental health. The psychological network analysis (which included only a subset of the variables listed above) depicted a 
similar pattern of results, showing that more time spent on video games is associated with increased response speed in attention tests, in addition to being a male and spending more time on media overall.

When considering video game play in general, our results are partially in agreement with the literature which so far has yielded mixed results. Pujol et al. (2016) for instance, tested over two thousand 7- to 11- year old children using a somewhat similar protocol to ours: children completed cognitive tests (of attention and working memory) and their parents and teachers filled out questionnaires about children's video gaming habits, their socioemotional functioning (using the Strength and Difficulties Questionnaire), their sleep and overall school achievement. In agreement with our results, their study shows that playing video games was linked with increased response speed without however affecting overall performance on the cognitive tests. Contrary to our results however, they observed a link between video gaming and sleep (more time on video games was linked to sleeping fewer hours). It remains unclear in the Pujol dataset, whether this relationship may be related to video gaming per se or to other associated variables like media multitasking.

In our study we found no direct relationship between time spent on video games and grades. Both the evidence and the opinions in the literature on how video gaming relates to academic performance are somewhat mixed. Some data on children and adolescents is compatible with video gaming being associated with greater school achievement (Kovess-Masfety et al., 2016; Pujol et al., 2016), while other suggests either no relationship or a small/moderate negative relationship for those children who play video games before going to school (Adelantado-Renau et al., 2019; Drummond \& Sauer, 2020; Ferguson, 2015). These mixed results are paralleled by different opinions on what relationship to expect. On the one hand, researchers have argued that some kinds of video games improve cognitive abilities which are thought to be crucial for academic performance (Stevens \& Bavelier, 2012); on the other, researchers expect video gaming to negatively impact academic performance by either taking away time from other activities, impairing sleep or the ability to concentrate in a slow paced school environment (e.g., Drummond \& Sauer, 2020; Weis \& Cerankosky, 2010). The present data do not support the view that video gaming impairs academic achievement as we find no direct relationship between video gaming and sleep (we do however see the well-known link between better sleep quality and better grades). Gaming might affect educational performance by improving cognition, albeit indirectly, given the link between video gaming and cognition (increased speed) and that between cognition and grades (lower impulsivity and inattention are linked to better grades). 
While our study does not resolve the many inconsistencies in the field of media and their impact on cognitive functioning, mental health, and school related variables, it clearly highlights a few major points. First, it is absolutely necessary to take into account not only total time on media, but also other, more specific measures of media consumption. Here we considered media multitasking and video game playing (in addition to total media time); it seems highly valuable for future studies to include social media, internet browsing or TV/video watching to cite a few. From this point of view, media-multitasking questionnaires could be further exploited to document these different forms of media consumption. Second, in the case of video games, the specific types of games that are played (e.g., action-like vs. non-action), how and when they are played (e.g., before or after school; in the morning versus evening) appear to be important factors to consider. As different video games have been shown to differently affect cognition, considering their impact separately may help explain some of the discrepancies in the literature (Cardoso-Leite, Ansarinia, Schmück, \& Bavelier, in-press; Cardoso-Leite et al., 2020). Third, while most empirical research focused on pairwise relationships (e.g., between playing video games and grades), researchers do in fact have implicit or explicit hypotheses of how specifically these variables relate (e.g., gaming improves educational attainment by improving attentional control)-the psychological network analysis presented in this study emerges as a powerful complementary tool to evaluate the plausibility of these hypotheses along with pairwise correlation.

\section{Psychological network analysis as a promising tool to study media effects on humans}

The psychological network analysis applied on this data set confirmed several wellknown results (unrelated to media use), further underlining the value of the approach. For instance, age was associated with increased attentional control abilities (increased response speed, reduced impulsivity and reduced inattention; Salkind \& Wright, 1977). Factoring out age, increased response speed was associated with greater impulsivity and greater inattention (as measured by more frequent false alarms and misses, respectively); this pattern of results reflects the well-known speed-accuracy tradeoff phenomenon. We also observed the expected relationships between academic grades and children's behavioral and attentional problems as rated by their teachers. Inattention, impulsivity, worse teacher rating and reduced sleep quality were unsurprisingly also directly associated with lower grades (Conard, 2006). Worse teacher ratings were in turn associated with inattention, lower sleep quality and being male (e.g., Bruni et al., 2006). Psychological network analysis therefore appears to be a very powerful tool to shed light on the relationships between multiple variables. It 
seems particularly well-suited to study the relationships between media consumption, attentional/behavioral control, mental health and academic achievement because many of these variables correlate with each other and their causal relationships remain largely unresolved. Applying psychological network analyses on a larger set of variables might provide a means to untangle some of the past results.

\section{Limitations of the present study}

We recognize this study has several important limitations. First, all the data reported here are correlational and as such provide no unequivocal indication about the causal relationships between any of the variables of interest. In particular, our study highlights that different types of media use are far from independent, calling for care when separating out direct relations. For example, media multitasking has been repeatedly associated with a greater tendency to mind wander (Ralph et al., 2014; but see Wiradhany et al., 2019) and we did observe such a relationship as well in simple pairwise correlations (pairwise Spearman correlations: $r=0.31 ; p=0.012$ ). Yet, we also observed a correlation between mind wandering and total hours of consumed media ( $r$ $=0.31 ; p=0.009$ ) which itself correlates with media multitasking (for completeness, note that hours of video gaming does not correlate with mind wandering; $r=0.16 ; p=$ 0.186). Such a pattern of results highlights the fact that it may be problematic to attribute the variations in mind wandering to media multitasking rather than to total hours of consumed media. Causal studies would certainly be highly valuable but may not be ethical given some of the negative impacts reported here and in the broader literature.

Second, given the number of tests and surveys used in the present study, it would have been desirable to include data from a larger population. For instance, while we have a nested structure for analysis (individual children are grouped in classes), we do not have the necessary size to perform such an analysis robustly. Third, while research has repeatedly indicated that the effects of video games on cognition depend largely on the video game genre (Bediou et al., 2018; Powers \& Brooks, 2014; Powers et al., 2013; Sala et al., 2018; Wang et al., 2016), we did not have sample sizes large enough to substantiate any claims regarding genre-specific effects. The modest or absent effects observed in the present study might turn out very differently if video gaming activity is considered with greater minutiae (e.g., action, social, puzzle). Fourth, although this study included numerous measures it is likely that important measures were missed and deserve to be investigated in future studies. For instance, social media use is not expected to have the same attentional/behavioral or mental health impact as playing video games (Dyson et al., 2016; Lin et al., 2016; Lobel, Engels, Stone, \& Granic, 2017). Finally, many of the measures collected in this study are self- 
reports and as such are subject to biases. It is well known, for instance, that selfreported media use questionnaires do not fully reflect real usage (e.g., Hampton, 2017; Greenberg et al., 2005; Rich, Bickham, \& Shrier, 2015). Objective measures of media consumption, such as event-sampling or usage monitoring, would be preferable (Scharkow, 2016).

\section{Conclusion}

This study shows that different aspects of media consumption have different relationships with attentional/behavioral outcomes, mental health and school relevant variables, and thus highlights the importance of using more granular assessments than just total media time.

It is not uncommon to read that time in front of screens should be limited. The present paper indicates that such aggregate measures of media consumption are not sufficient and documents that the type of media used as well as how they are consumed both have differential impact. In this study, we are able to highlight such differences through multiple related, but distinct, media use measures, and by using partial correlations and psychological networks. These analyses reveal that media multitasking more than video gaming and total time on media was associated with adverse psychological outcomes and that media multitasking should therefore be considered more intensively in future studies.

Finally, the complexity of measuring media consumption calls for a paradigm shift that integrates real-life usage sampling, event sampling along with self-reports. Given the rapidly changing landscape of digital media and the complexity of the topic it would seem beneficial for the field to coordinate multi-lab studies and to systematically share data and methods on best practice to representatively and usefully sample media consumption. 


\section{References}

Adelantado-Renau, M., Moliner-Urdiales, D., Cavero-Redondo, I., Beltran-Valls, M. R., MartínezVizcaíno, V., \& Álvarez-Bueno, C. (2019). Association Between Screen Media Use and Academic Performance Among Children and Adolescents: A Systematic Review and Meta-analysis. JAMA Pediatrics, 173(11), 1058. https://doi.org/10.1001/jamapediatrics.2019.3176

Allen, M. S., \& Vella, S. A. (2015). Screen-based sedentary behaviour and psychosocial well-being in childhood: Cross-sectional and longitudinal associations. Mental Health and Physical Activity, 9, 41-47. https://doi.org/10.1016/j.mhpa.2015.10.002

Alzahabi, R., \& Becker, M. W. (2013). The association between media multitasking, task-switching, and dual-task performance. Journal of Experimental Psychology: Human Perception and Performance, 39(5), 1485-1495. https://doi.org/10.1037/a0031208

Aypay, A. (2010). Information and Communication Technology (ICT) Usage and Achievement of Turkish Students in Pisa 2006. Turkish Online Journal of Educational Technology - TOJET, 9(2), 116-124.

Retrieved from https://eric.ed.gov/?id=EJ898009

Baumgartner, S. E., \& Sumter, S. R. (2017). Dealing with media distractions: An observational study of computer-based multitasking among children and adults in the Netherlands. Journal of Children and Media, 11(3), 295-313. https://doi.org/10.1080/17482798.2017.1304971

Baumgartner, S. E., van der Schuur, W. A., Lemmens, J. S., \& te Poel, F. (2018). The Relationship Between Media Multitasking and Attention Problems in Adolescents: Results of Two Longitudinal Studies. Human Communication Research, 44(1), 3-30. https://doi.org/10.1093/hcre.12111

Baumgartner, S. E., Weeda, W. D., Heijden, L. L. van der, \& Huizinga, M. (2014). The Relationship Between Media Multitasking and Executive Function in Early Adolescents: The Journal of Early Adolescence. https://doi.org/10.1177/0272431614523133

Bavelier, D. (2018). Panel on the relationship between Cognition and Media Behavior. Presented at the Digital Media and Developing Mind, Cold Sping Harbor Conference. Retrieved from https://www.childrenandscreens.com/2018-conference/

Bavelier, D., Green, C. S., \& Dye, M. W. (2010). Children, Wired: For Better and for Worse. Neuron, 67(5), 692-701. https://doi.org/10.1016/j.neuron.2010.08.035

Becker, M. W., Alzahabi, R., \& Hopwood, C. J. (2013). Media Multitasking Is Associated with Symptoms of Depression and Social Anxiety. Cyberpsychology, Behavior, and Social Networking, 16(2), 132-135. https://doi.org/10.1089/cyber.2012.0291

Bediou, B., Adams, D. M., Mayer, R. E., Tipton, E., Green, C. S., \& Bavelier, D. (2018). Meta-analysis of action video game impact on perceptual, attentional, and cognitive skills. Psychological Bulletin, 144(1), 77-110. https://doi.org/10.1037/bul0000130

Bediou, B., Rich, M., \& Bavelier, D. (2020). Digital media and cognitive development. https://doi.org/https://doi-org.proxy.bnl.lu/10.1787/3b071e13-en

Beyens, I., Valkenburg, P. M., \& Piotrowski, J. T. (2018). Screen media use and ADHD-related behaviors: Four decades of research. Proceedings of the National Academy of Sciences, 115(40), 9875-9881. https://doi.org/10.1073/pnas.1611611114 
Bodson, L. (2017). Regards sur les activités quotidiennes des jeunes résidents. Luxembourg: Institut national de la statistique et des études économiques (STATEC).

Borsboom, D., \& Cramer, A. O. (2013). Network Analysis: An Integrative Approach to the Structure of Psychopathology. Annual Review of Clinical Psychology, 9(1), 91-121. https://doi.org/10.1146/annurevclinpsy-050212-185608

Brickenkamp, R., \& Zillmer, E. (1998). The d2 test of attention. Hogrefe \& Huber Seattle, WA.

Bruni, O., Ferinistrambi, L., Russo, P., Antignani, M., Innocenzi, M., Ottaviano, P., ... Ottaviano, S. (2006). Sleep disturbances and teacher ratings of school achievement and temperament in children. Sleep Medicine, 7(1), 43-48. https://doi.org/10.1016/j.sleep.2005.09.003

Bulut, O., \& Cutumisu, M. (2017). When Technology Does Not Add Up: ICT Use Negatively Predicts Mathematics and Science Achievement for Finnish and Turkish Students in PISA 2012. In (pp. 935-945). Presented at the EdMedia + Innovate Learning, Association for the Advancement of Computing in Education (AACE). Retrieved from https://www.learntechlib.org/primary/p/178407/

Cain, M. S., Leonard, J. A., Gabrieli, J. D. E., \& Finn, A. S. (2016). Media multitasking in adolescence. Psychonomic Bulletin \& Review, 23(6), 1932-1941. https://doi.org/10.3758/s13423-016-1036-3

Calamaro, C. J., Mason, T. B. A., \& Ratcliffe, S. J. (2009). Adolescents Living the 24/7 Lifestyle: Effects of Caffeine and Technology on Sleep Duration and Daytime Functioning. PEDIATRICS, 123(6), e1005e1010. https://doi.org/10.1542/peds.2008-3641

Cardoso-Leite, P., Ansarinia, M., Schmück, E., \& Bavelier, D. (in-press). Training Cognition with videogames. In K. Cohen-Kadosh (Ed.), Oxford Handbook of Developmental Cognitive Neuroscience. Oxford University Press.

Cardoso-Leite, P., \& Bavelier, D. (2014). Video game play, attention, and learning: How to shape the development of attention and influence learning? Current Opinion in Neurology, 27(2), 185-191. https://doi.org/10.1097/WCO.0000000000000077

Cardoso-Leite, P., Joessel, A., \& Bavelier, D. (2020). Games for enhancing cognitive abilities. In J. Plass, R. E. Mayer, \& B. D. Homer (Eds.), Handbook of Game-based Learning. Boston: MIT Press. Retrieved from https://mitpress. mit.edu/books/handbook-game-based-learning

Cardoso-Leite, P., Kludt, R., Vignola, G., Ma, W. J., Green, C. S., \& Bavelier, D. (2016). Technology consumption and cognitive control: Contrasting action video game experience with media multitasking. Attention, Perception, \& Psychophysics, 78(1), 218-241. Retrieved from

http://link.springer.com/article/10.3758/s13414-015-0988-0

Chaput, J.-P., Gray, C. E., Poitras, V. J., Carson, V., Gruber, R., Olds, T., ... Tremblay, M. S. (2016). Systematic review of the relationships between sleep duration and health indicators in school-aged children and youth. Applied Physiology, Nutrition, and Metabolism, 41(6 (Suppl. 3)), S266-S282. https://doi.org/10.1139/apnm-2015-0627

Cheever, N. A., Peviani, K., \& Rosen, L. D. (2018). Media Multitasking and Mental Health. In M. A. Moreno \& A. Radovic (Eds.), Technology and Adolescent Mental Health (pp. 101-112). Cham: Springer International Publishing. https://doi.org/10.1007/978-3-319-69638-6_8

Clifford, S., Doane, L. D., Breitenstein, R., Grimm, K. J., \& Lemery-Chalfant, K. (2020). Effortful Control Moderates the Relation Between Electronic-Media Use and Objective Sleep Indicators in Childhood. Psychological Science, 31(7), 822-834. https://doi.org/10.1177/0956797620919432 
Conard, M. A. (2006). Aptitude is not enough: How personality and behavior predict academic performance. Journal of Research in Personality, 40(3), 339-346.

https://doi.org/10.1016/j.jrp.2004.10.003

Conners, C. (1997). Conners' Rating Scales-Revised technical manual. North Tonawanda, NY: MultiHealth Systems.

Cotten, S. R., Shank, D. B., \& Anderson, W. A. (2014). Gender, technology use and ownership, and media-based multitasking among middle school students. Computers in Human Behavior, 35, 99-106. https://doi.org/10.1016/j.chb.2014.02.041

Domoff, S. E., Harrison, K., Gearhardt, A. N., Gentile, D. A., Lumeng, J. C., \& Miller, A. L. (2019). Development and Validation of the Problematic Media Use Measure: A Parent Report Measure of Screen Media "Addiction" in Children. Psychology of Popular Media Culture, 8(1), 2-11.

https://doi.org/10.1037/ppm0000163

Drummond, A., \& Sauer, J. D. (2020). Timesplitters: Playing video games before (but not after) school on weekdays is associated with poorer adolescent academic performance. A test of competing theoretical accounts. Computers \& Education, 144, 103704. https://doi.org/10.1016/j.compedu.2019.103704

Duckworth, A. L., Peterson, C., Matthews, M. D., \& Kelly, D. R. (2007). Grit: Perseverance and passion for long-term goals. Journal of Personality and Social Psychology, 92(6), 1087-1101.

https://doi.org/10.1037/0022-3514.92.6.1087

Dweck, C. S. (2008). Mindset: The new psychology of success (Ballantine Books trade pbk. ed). New York: Ballantine Books.

Dye, M. W., \& Bavelier, D. (2010). Differential development of visual attention skills in school-age children. Vision Research, 50(4), 452-459. https://doi.org/10.1016/j.visres.2009.10.010

Dyson, M. P., Hartling, L., Shulhan, J., Chisholm, A., Milne, A., Sundar, P., ... Newton, A. S. (2016). A Systematic Review of Social Media Use to Discuss and View Deliberate Self-Harm Acts. PLOS ONE, 11(5), e0155813. https://doi.org/10.1371/journal.pone.0155813

Elbe, P., Sörman, D. E., Mellqvist, E., Brändström, J., \& Ljungberg, J. K. (2019). Predicting attention shifting abilities from self-reported media multitasking. Psychonomic Bulletin \& Review, 26(4), 12571265. https://doi.org/10.3758/s13423-018-01566-6

Epskamp, S., Borsboom, D., \& Fried, E. I. (2018). Estimating psychological networks and their accuracy: A tutorial paper. Behavior Research Methods, 50(1), 195-212. https://doi.org/10.3758/s13428-017-08621

Ferguson, C. J. (2015). Do Angry Birds Make for Angry Children? A Meta-Analysis of Video Game Influences on Children's and Adolescents' Aggression, Mental Health, Prosocial Behavior, and Academic Performance. Perspectives on Psychological Science: A Journal of the Association for Psychological Science, 10(5), 646-666. https://doi.org/10.1177/1745691615592234

Franceschini, S., Gori, S., Ruffino, M., Viola, S., Molteni, M., \& Facoetti, A. (2013). Action Video Games Make Dyslexic Children Read Better. Current Biology, 23(6), 462-466.

https://doi.org/10.1016/j.cub.2013.01.044

Franceschini, S., Trevisan, P., Ronconi, L., Bertoni, S., Colmar, S., Double, K., ... Gori, S. (2017). Action video games improve reading abilities and visual-to-auditory attentional shifting in English-speaking children with dyslexia. Scientific Reports, 7(1). https://doi.org/10.1038/s41598-017-05826-8 
Goodman, R. (1997). The Strengths and Difficulties Questionnaire: A research note. Journal of Child Psychology and Psychiatry, and Allied Disciplines, 38(5), 581-586.

Greenberg, B. S., Eastin, M. S., Skalski, P., Cooper, L., Levy, M., \& Lachlan, K. (2005). Comparing Survey and Diary Measures of Internet and Traditional Media Use. Communication Reports, 18(1-2), 1-8. https://doi.org/10.1080/08934210500084164

Hampton, K. N. (2017). Studying the Digital: Directions and Challenges for Digital Methods. Annual Review of Sociology, 43(1), 167-188. https://doi.org/10.1146/annurev-soc-060116-053505

Hartanto, A., Toh, W. X., \& Yang, H. (2018). Context counts: The different implications of weekday and weekend video gaming for academic performance in mathematics, reading, and science. Computers \& Education, 120, 51-63. https://doi.org/10.1016/j.compedu.2017.12.007

Kessler, R. C., Barker, P. R., Colpe, L. J., Epstein, J. F., Gfroerer, J. C., Hiripi, E., ... Zaslavsky, A. M. (2003). Screening for serious mental illness in the general population. Archives of General Psychiatry, 60(2), 184-189.

Kobayashi, K., Oishi, N., Yoshimura, S., Ueno, T., Miyagi, T., Murai, T., \& Fujiwara, H. (2020). Relationship between media multitasking and functional connectivity in the dorsal attention network. Scientific Reports, 10(1, 1), 17992. https://doi.org/10.1038/s41598-020-75091-9

Kovess-Masfety, V., Keyes, K., Hamilton, A., Hanson, G., Bitfoi, A., Golitz, D., ... Pez, O. (2016). Is time spent playing video games associated with mental health, cognitive and social skills in young children? Social Psychiatry and Psychiatric Epidemiology, 51(3), 349-357. https://doi.org/10.1007/s00127-016$1179-6$

Lange, K., Cohrs, S., Skarupke, C., Görke, M., Szagun, B., \& Schlack, R. (2017). Electronic media use and insomnia complaints in German adolescents: Gender differences in use patterns and sleep problems. Journal of Neural Transmission, 124(S1), 79-87. https://doi.org/10.1007/s00702-015-1482-5

Libertus, M. E., Liu, A., Pikul, O., Jacques, T., Cardoso-Leite, P., Halberda, J., \& Bavelier, D. (2017). The Impact of Action Video Game Training on Mathematical Abilities in Adults. AERA Open, 3(4), 233285841774085. https://doi.org/10.1177/2332858417740857

Limtrakul, N., Louthrenoo, O., Narkpongphun, A., Boonchooduang, N., \& Chonchaiya, W. (2018). Media use and psychosocial adjustment in children and adolescents. Journal of Paediatrics and Child Health, 54(3), 296-301. https://doi.org/10.1111/jpc.13725

Lin, L. yi, Sidani, J. E., Shensa, A., Radovic, A., Miller, E., Colditz, J. B., ... Primack, B. A. (2016). ASSOCIATION BETWEEN SOCIAL MEDIA USE AND DEPRESSION AMONG U.S. YOUNG ADULTS: Research Article: Social Media and Depression. Depression and Anxiety, 33(4), 323-331. https://doi.org/10.1002/da.22466

Lobel, A., Engels, R. C. M. E., Stone, L. L., \& Granic, I. (2017). Gaining a competitive edge: Longitudinal associations between children's competitive video game playing, conduct problems, peer relations, and prosocial behavior. Psychology of Popular Media Culture. https://doi.org/10.1037/ppm0000159

Loh, K. K., Tan, B. Z. H., \& Lim, S. W. H. (2016). Media multitasking predicts video-recorded lecture learning performance through mind wandering tendencies. Computers in Human Behavior, 63, 943-947. https://doi.org/10.1016/j.chb.2016.06.030

Luo, J., Yeung, P.-S., \& Li, H. (2020). The relationship among media multitasking, academic performance and self-esteem in Chinese adolescents: The cross-lagged panel and mediation analyses. Children and Youth Services Review, 117, 105308. https://doi.org/10.1016/j.childyouth.2020.105308 
Madore, K. P., Khazenzon, A. M., Backes, C. W., Jiang, J., Uncapher, M. R., Norcia, A. M., \& Wagner, A. D. (2020). Memory failure predicted by attention lapsing and media multitasking. Nature, 587(7832, 7832), 87-91. https://doi.org/10.1038/s41586-020-2870-z

Magen, H. (2017). The relations between executive functions, media multitasking and polychronicity. Computers in Human Behavior, 67, 1-9. https://doi.org/10.1016/j.chb.2016.10.011

Martín-Perpiñá, M. de las M., Viñas i Poch, F., \& Malo Cerrato, S. (2019). Media multitasking impact in homework, executive function and academic performance in Spanish adolescents. Martin-Perpiná, Mercedes Viñas I Poch, Ferran Malo Cerrato, Sara 2019 Media Multitasking Impact in Homework, Executive Function and Academic Performance in Spanish Adolescents Psicothema 3118187. https://doi.org/10.7334/psicothema2018.178

Minear, M., Brasher, F., McCurdy, M., Lewis, J., \& Younggren, A. (2013). Working memory, fluid intelligence, and impulsiveness in heavy media multitaskers. Psychonomic Bulletin \& Review, 20(6), 1274-81. https://doi.org/10.3758/s13423-013-0456-6

Mrazek, M. D., Phillips, D. T., Franklin, M. S., Broadway, J. M., \& Schooler, J. W. (2013). Young and restless: Validation of the Mind-Wandering Questionnaire (MWQ) reveals disruptive impact of mindwandering for youth. Frontiers in Psychology, 4. https://doi.org/10.3389/fpsyg.2013.00560

Nikkelen, S. W. C., Valkenburg, P. M., Huizinga, M., \& Bushman, B. J. (2014). Media use and ADHDrelated behaviors in children and adolescents: A meta-analysis. Developmental Psychology, 50(9), 22282241. https://doi.org/10.1037/a0037318

Ophir, E., Nass, C., \& Wagner, A. D. (2009). Cognitive control in media multitaskers. Proceedings of the National Academy of Sciences of the United States of America, 106(37), 15583-7.

https://doi.org/10.1073/pnas.0903620106

Orben, A., \& Przybylski, A. K. (2019). The association between adolescent well-being and digital technology use. Nature Human Behaviour. https://doi.org/10.1038/s41562-018-0506-1

Owens, J., ADOLESCENT SLEEP WORKING GROUP, \& COMMITTEE ON ADOLESCENCE. (2014). Insufficient Sleep in Adolescents and Young Adults: An Update on Causes and Consequences. PEDIATRICS, 134(3), e921-e932. https://doi.org/10.1542/peds.2014-1696

Parong, J., \& Mayer, R. E. (2018). Learning science in immersive virtual reality. Journal of Educational Psychology, 110(6), 785-797. https://doi.org/10.1037/edu0000241

Parry, D. A., \& le Roux, D. B. (2019). Media multitasking and cognitive control: A systematic review of interventions. Computers in Human Behavior, 92, 316-327. https://doi.org/10.1016/j.chb.2018.11.031

Pea, R., Nass, C., Meheula, L., Rance, M., Kumar, A., Bamford, H., ... Zhou, M. (2012). Media use, faceto-face communication, media multitasking, and social well-being among 8- to 12-year-old girls.

Developmental Psychology, 48(2), 327-336. https://doi.org/10.1037/a0027030

Petton, M., Perrone-Bertolotti, M., Mac-Auliffe, D., Bertrand, O., Aguera, P.-E., Sipp, F., ... Lachaux, J.P. (2018). BLAST : A short computerized test to measure the ability to stay on task. Normative behavioral data and detailed cortical dynamics. bioRxiv. https://doi.org/10.1101/498691

Posso, A. (2016). Internet usage and educational outcomes among 15-year old Australian students. International Journal of Communication, 10, 26.

Powers, K. L., \& Brooks, P. J. (2014). Evaluating the Specificity of Effects of Video Game Training. In F. C. Blumberg (Ed.), Learning by Playing (pp. 302-330). Oxford University Press.

https://doi.org/10.1093/acprof:osobl/9780199896646.003.0021 
Powers, K. L., Brooks, P. J., Aldrich, N. J., Palladino, M. A., \& Alfieri, L. (2013). Effects of video-game play on information processing: A meta-analytic investigation. Psychonomic Bulletin \& Review, 20(6), 1055-1079. https://doi.org/10.3758/s13423-013-0418-z

Przybylski, A. K. (2014). Electronic Gaming and Psychosocial Adjustment. Pediatrics, 134(3), e716-e722. https://doi.org/10.1542/peds.2013-4021

Pujol, J., Fenoll, R., Forns, J., Harrison, B. J., Martinez-Vilavella, G., Macià, D., ... Sunyer, J. (2016). Video gaming in school children: How much is enough? Annals of Neurology, 80(3), 424-433.

https://doi.org/10.1002/ana.24745

Ra, C. K., Cho, J., Stone, M. D., De La Cerda, J., Goldenson, N. I., Moroney, E., ... Leventhal, A. M. (2018). Association of Digital Media Use With Subsequent Symptoms of Attention-Deficit/Hyperactivity Disorder Among Adolescents. JAMA, 320(3), 255. https://doi.org/10.1001/jama.2018.8931

Ralph, B. C. W., Thomson, D. R., Cheyne, J. A., \& Smilek, D. (2014). Media multitasking and failures of attention in everyday life. Psychological Research, 78(5), 661-669. https://doi.org/10.1007/s00426-0130523-7

Reilly, D., Neumann, D. L., \& Andrews, G. (2017). Gender Differences in Spatial Ability: Implications for STEM Education and Approaches to Reducing the Gender Gap for Parents and Educators. In M. S. Khine (Ed.), Visual-spatial Ability in STEM Education: Transforming Research into Practice (pp. 195-224). Cham: Springer International Publishing. https://doi.org/10.1007/978-3-319-44385-0_10

Rich, M., Bickham, D. S., \& Shrier, L. A. (2015). Measuring Youth Media Exposure: A Multimodal Method for Investigating the Influence of Media on Digital Natives. American Behavioral Scientist, 59(14), 17361754. https://doi.org/10.1177/0002764215596558

Rideout, V. (2015). The Common Sense Census: Media Use by Tweens and Teens (p. 104). San Francisco: Common Sense Media. Retrieved from https://www.commonsensemedia.org/sites/default/files/uploads/research/census_researchreport.pdf

Rideout, V. J., Foehr, U. G., \& Roberts, D. F. (2010). Generation M 2: Media in the Lives of 8-to 18-YearOlds. Henry J. Kaiser Family Foundation.

Rideout, V. J., Vandewater, E. A., \& Wartella, E. A. (2003). Zero to six: Electronic media in the lives of infants, toddlers and preschoolers.

Roberts, D., Foehr, U., \& Rideout, V. (2005). Generation M: Media in the Lives of 8-18 Year-Olds, Kaiser Family Foundation. March. Http://Www. Kff. Org/Entmedia/Entmedia030905nr. Cfm.

Robertson, I. H., Manly, T., Andrade, J., Baddeley, B. T., \& Yiend, J. (1997). “Oops!”: Performance correlates of everyday attentional failures in traumatic brain injured and normal subjects.

Neuropsychologia, 35(6), 747-758. https://doi.org/10.1016/S0028-3932(97)00015-8

Rogobete, D. A., Ionescu, T., \& Miclea, M. (2020). The Relationship Between Media Multitasking Behavior and Executive Function in Adolescence: A Replication Study. The Journal of Early Adolescence, 0272431620950478. https://doi.org/10.1177/0272431620950478

Sala, G., Tatlidil, K. S., \& Gobet, F. (2018). Video game training does not enhance cognitive ability: A comprehensive meta-analytic investigation. Psychological Bulletin, 144(2), 111-139.

https://doi.org/10.1037/bul0000139

Salkind, N. J., \& Wright, J. C. (1977). The development of reflection-impulsivity and cognitive efficiency. Human Development, 20(6), 377-387. 
Sanbonmatsu, D. M., Strayer, D. L., Medeiros-Ward, N., \& Watson, J. M. (2013). Who Multi-Tasks and Why? Multi-Tasking Ability, Perceived Multi-Tasking Ability, Impulsivity, and Sensation Seeking. PLoS ONE, 8(1), e54402. https://doi.org/10.1371/journal.pone.0054402

Scharkow, M. (2016). The Accuracy of Self-Reported Internet Use-A Validation Study Using Client Log Data. Communication Methods and Measures, 10(1), 13-27.

https://doi.org/10.1080/19312458.2015.1118446

School grade placement. (2019). Stamford American International School Singapore. Retrieved from https://www.sais.edu.sg/admissions/grade-listings/

Seddon, A. L., Law, A. S., Adams, A.-M., \& Simmons, F. R. (2018). Exploring the relationship between executive functions and self-reported media-multitasking in young adults. Journal of Cognitive Psychology, 30(7), 728-742. https://doi.org/10.1080/20445911.2018.1525387

Shin, M., Linke, A., \& Kemps, E. (2020). Moderate amounts of media multitasking are associated with optimal task performance and minimal mind wandering. Computers in Human Behavior, 111, 106422. https://doi.org/10.1016/j.chb.2020.106422

Shin, M., Webb, A., \& Kemps, E. (2019). Media multitasking, impulsivity and dual task ability. Computers in Human Behavior, 92, 160-168. https://doi.org/10.1016/j.chb.2018.11.018

Srisinghasongkram, P., Trairatvorakul, P., Maes, M., \& Chonchaiya, W. (2020). Effect of early screen media multitasking on behavioural problems in school-age children. European Child \& Adolescent Psychiatry. https://doi.org/10.1007/s00787-020-01623-3

Stevens, C., \& Bavelier, D. (2012). The role of selective attention on academic foundations: A cognitive neuroscience perspective. Developmental Cognitive Neuroscience, 2, S30-S48.

https://doi.org/10.1016/j.dcn.2011.11.001

Stiglic, N., \& Viner, R. M. (2019). Effects of screentime on the health and well-being of children and adolescents: A systematic review of reviews. BMJ Open, 9(1), e023191.

https://doi.org/10.1136/bmjopen-2018-023191

Team, R. C. (2013). R: A language and environment for statistical computing.

Toril, P., Reales, J. M., \& Ballesteros, S. (2014). Video game training enhances cognition of older adults: A meta-analytic study. Psychology and Aging, 29(3), 706-716. https://doi.org/10.1037/a0037507

Twenge, J. M., \& Campbell, W. K. (2018). Associations between screen time and lower psychological well-being among children and adolescents: Evidence from a population-based study. Preventive Medicine Reports, 12, 271-283. https://doi.org/10.1016/j.pmedr.2018.10.003

Uncapher, M. R., K. Thieu, M., \& Wagner, A. D. (2016). Media multitasking and memory: Differences in working memory and long-term memory. Psychonomic Bulletin \& Review, 23(2), 483-490.

https://doi.org/10.3758/s13423-015-0907-3

Uncapher, M. R., Lin, L., Rosen, L. D., Kirkorian, H. L., Baron, N. S., Bailey, K., .. Wagner, A. D. (2017). Media Multitasking and Cognitive, Psychological, Neural, and Learning Differences. Pediatrics, 140(Supplement 2), S62-S66. https://doi.org/10.1542/peds.2016-1758D

Uncapher, M. R., \& Wagner, A. D. (2018). Minds and brains of media multitaskers: Current findings and future directions. Proceedings of the National Academy of Sciences, 115(40), 9889-9896.

https://doi.org/10.1073/pnas.1611612115 
Uzun, A. M., \& Kilis, S. (2019). Does persistent involvement in media and technology lead to lower academic performance? Evaluating media and technology use in relation to multitasking, self-regulation and academic performance. Computers in Human Behavior, 90, 196-203.

https://doi.org/10.1016/j.chb.2018.08.045

van der Schuur, W. A., Baumgartner, S. E., Sumter, S. R., \& Valkenburg, P. M. (2018). Media multitasking and sleep problems: A longitudinal study among adolescents. Computers in Human Behavior, 81, 316324. https://doi.org/10.1016/j.chb.2017.12.024

Ventura, M., Shute, V., \& Kim, Y. J. (2012). Video gameplay, personality and academic performance. Computers \& Education, 58(4), 1260-1266. https://doi.org/10.1016/j.compedu.2011.11.022

Wang, P., Liu, H.-H., Zhu, X.-T., Meng, T., Li, H.-J., \& Zuo, X.-N. (2016). Action Video Game Training for Healthy Adults: A Meta-Analytic Study. Frontiers in Psychology, 7.

https://doi.org/10.3389/fpsyg.2016.00907

Weis, R., \& Cerankosky, B. C. (2010). Effects of Video-Game Ownership on Young Boys' Academic and Behavioral Functioning: A Randomized, Controlled Study. Psychological Science, 21(4), 463-470.

https://doi.org/10.1177/0956797610362670

Wiradhany, W., \& Nieuwenstein, M. R. (2017). Cognitive control in media multitaskers: Two replication studies and a meta-Analysis. Attention, Perception, and Psychophysics, (Mmi).

https://doi.org/10.3758/s13414-017-1408-4

Wiradhany, W., van Vugt, M. K., \& Nieuwenstein, M. R. (2019). Media multitasking, mind-wandering, and distractibility: A large-scale study. Attention, Perception, \& Psychophysics.

https://doi.org/10.3758/s13414-019-01842-0

Wiradhany, W., van Vugt, M. K., \& Nieuwenstein, M. R. (2020). Media multitasking, mind-wandering, and distractibility: A large-scale study. Attention, Perception, \& Psychophysics, 82(3), 1112-1124.

https://doi.org/10.3758/s13414-019-01842-0

Zhao, J., Zhang, Y., Jiang, F., Ip, P., Ho, F. K. W., Zhang, Y., \& Huang, H. (2018). Excessive Screen Time and Psychosocial Well-Being: The Mediating Role of Body Mass Index, Sleep Duration, and Parent-Child Interaction. The Journal of Pediatrics, 202, 157-162.e1. https://doi.org/10.1016/j.jpeds.2018.06.029 